\title{
Digital Library Initiatives: A Boon for Preservation of Information Resources in India
}

\author{
Geeta Kitturand ${ }^{1}$, Kavita Biradar ${ }^{2}$ \\ ${ }^{1}$ Chief Librarian, Dharwad Advocates Bar Association, Dharwad- 580001 \\ ${ }^{2}$ Research Scholar, Department of Library and Information Science, Bangalore University, Bangalore-560056
}

\begin{abstract}
The emergence of digital technology is a process of storage, retrieval and dissemination of information has made the traditional libraries to go digital. Librariesall around the world have responded to diverse challenges posed by preservation of digital information and have encountered the technical, organizational, resource and legal issues associated with it. The paper highlights brief about thedigital library preservation, challenges and opportunity, software like LOCKSS, E-prints, D-space, Depot, Fedora, Greenstone etc which are useful for developing digital libraries and digital library initiatives in India.
\end{abstract}

Keywords: Digital Library, Digital Library Softwares, Information Preservation, Information Storage, Digital Library Initiatives

\section{Introduction}

The first and foremost motto of library is providing the right Information to the right users at the right time in right manner. The information and communication technology particularly the Internet and the Web, have brought massive changes in the ways of information preservation, dissemination, access, and use. In earlier days the information was being made available in printed format. However, with the advancement of information and communication technology(ICT), the situation has changingrapidly as the printed information is converted into electronic format and available for use with the help of the information and communication technologies. This resulted in development of digital libraries at publishers, institutional and at individual's level to provide access to scholarly literature through World Wide Web (WWW). Today, the developmentof digital libraries is fast picking up both in developedand developing countries using both commercialand open source software. This has changed theway in which information is being delivered to endusersby the libraries.

\section{Digital Libraries and Preservation}

Digital preservation is the exploration of systematic approaches to ingest, archive, and disseminate digitized information. The development of digital preservation is heavily influenced by the use of electronic devices such as personal computers, electronic game devices, mobiles, digital cameras, digital recorders, and digital TVs.

Digital preservation is a process by which data is preserved in digital form in order to ensure usability, durability and intellectual integrity of the information contained therein. "the storage, maintenance, and accessibility of digital object (include any digital material such as a text document, an image file, a multimedia CD-ROM or a database) over long term, usually as a consequence of applying one or more digital preservation strategies. A digital preservation strategy should be evaluated against a set of criteria such as technological feasibility, cost-effectiveness, effectiveness in retaining the essential attributes of digital information, acceptance by creators, managers of digital repositories, and user communities.

\section{Challenges and Opportunities}

- Building digital collections of national importance from existing texts, documents, images

- Creating new digital documents \& linking them

- Subject portals: Selecting and maintaining open source digital resources

- Developing / adapting management tools for digital collections

- Providing access to digital collections

- Integrating digital \& other library collections

- integration of OPACs, subscribed e-resources and subject portals

- Establishing services for digital libraries

- online access \& offline support

- education \& training of users and librarians

- Addressing social, legal, policy issues

- Outsourcing digitization and services.

\section{Software for Digital Libraries}

\section{LOCKSS}

LOCKSS (Lots of Copies Keep Stuff Safe) is an opensource system under the auspices of the Stanford University. LOCKSS is a distributed, peer-to-peer preservation system that is able to manage multiple copies at remote data repositories. The system was released in 2004 and had been tested at more than 50 libraries worldwide.

\section{Eprints}

EPrints is free software developed by the University of Southampton, England. ePrints@IISc repository collects preserves and disseminates in digital format the research output created by the IISc research community. It enables the Institute community to deposit their preprints; post prints and other scholarly publications using a web interface, and organizes 


\section{International Journal of Science and Research (IJSR) \\ ISSN (Online): 2319-7064}

Index Copernicus Value (2015): 78.96 | Impact Factor (2015): 6.391

\section{D-Space}

D-Space is a digital library system to capture, store, index, preserveand re-distribute the intellectual output of a university's researchfaculty in digital formats. D-space has been developed jointly byMIT Libraries and HewlettPackard (HP). It is now freely availableto research institutions world-wide as an open source systeme-

\section{Depot \\ e-Depot (E. Oltmans and H. V. Wijngaarden 2004) is a long- term preservation system developed by the National Library of Netherlands. The core part of e-Depot is the DIAS that was developed by IBM. The objective of e-Depot is to maintain the integrity of stored digital objects so that these objects are accessible.}

\section{Fedora}

FEDORA (Flexible Extensible Digital Object Repository Architecture) is constructed under an open-source digital preservation infrastructure. FEDORA began in 1997, headed by the Cornell University and University of Virginia. In the latest version, FEDORA provides not only the basic functions of preservation systems, but also a model using semantic techniques, i.e., the Resource Description Framework (RDF) maintaining relations between digital objects.

\section{Greenstone \\ Greenstone is a tool for creating and managing digital library collections. Runningon Windows as well as various flavors of UNIX, it provides the means to easily create searchableand browse able interfaces to digital library collections via the Web. It also enables implementers tosave their collections to CDs. Thus the digital library collections can be distributed to people withpoor or not Internet access. Greenstone knows how to create collections from "standard" fileformats such as HTML files, email messages, PDF documents, JPEG and GIF images, Worddocuments, as well as plain text files. It has been developed and distributed in cooperation with UNESCO and the Human Info NGO inBelgium.}

\section{Digital Library Initiatives in India}

In India, a number of digital library initiatives and digitization programmes have been initiated across the country. Some of the important initiatives are discussed below.

\section{Digital Library of India \\ Digital Library of India (DLI) is the biggest national level digital library initiative in India. It is a part of the Universal Digital Library Project, envisaged by Carnegie Mellon University, USA, which has some other international partners such as China and Egypt. DLI is coordinated by Indian Institute of Science, Bangalore and is supported by Ministry of Communications and Information Technology, Government of India. The Mission is to create a portal for the Digital Library of India which will foster creativity and free access to all human knowledge. As a first step in realizing this mission, it is proposed to create the Digital Library of one million books, predominantly in Indian languages, available to everyone over the Internet. This}

portal will also become an aggregator of all the knowledge and digital content created by other digitallibrary initiatives in India.

\section{Traditional Knowledge Digital Library (TKDL)}

A project called Traditional Knowledge Digital Library (TKDL) initiated in 2001 is a collaborative one between Council of Scientific and Industrial Research (CSIR), Ministry of Science and Technology and Department of AYUSH, Ministry of Health and Family Welfare, which is implanted at CSIR. TKDL preserves the information in languages and formats understandable by the patent examiners at International Patent Officers (IPOs), to avoid issuing of patent wrongly. Many personnel such as technical experts, team of traditional medicine, Information Technology experts, patent examiners and scientists are involved in the project. This project involves in documenting traditional knowledge such as Ayurveda, siddha, Unani, Yoga in digitized form in five international languages (English, German, French, Japanese, and Spanish)

\section{Down the Memory Lane}

The National Library of India has initiated in late 1990s a digitization programme, known as 'Down the Memory Lane', to digitize rare books, manuscripts and other resources from its collection. The English books that were published prior to 1900 and Indian books published before 1920 were taken into consideration. Similarly, the Central Secretariat Library has initiated a programme to digitize government publications like, Gazette of India, Commission \& Committee Reports, Annual Reports of the Ministries.

\section{Indira Gandhi National Centre for the Arts (IGNCA)- Kalasampada \\ Indira Gandhi National Centre for Arts (IGNCA), established a Digital Library, known as"Kalasampada", (Digital Library Resource for Indian Cultural Heritage). It includes non-print aswell as printed materials. The users will have access to the highly researched publications ofthe IGNCA from a single window. The integration of multimedia computer technology andsoftware provides a new dimension in the study of the Indian Art and Culture.}

\section{Indian Parliament Library}

This library serves members of Parliament and officers and staff of Lok Sabha Secretariat. Largedatabases were initially developed by the computer centre. The data are stored and available now inPARLIS (Parliament Library Information System).

\section{Khuda Baksh Oriental Public Library}

The Khuda Baksh Oriential Public Library has initiated digitization of Arabic and Persianmanuscripts of the medieval India. It is one of the Oriental Libraries having rich collection ofPersian, Arabic, Urdu and other languages manuscripts.

\section{National Mission for Manuscripts}

As a part of the digitization efforts, the Department of Culture, Ministry of Tourism and Culture, Government of India, launched the National Mission for Manuscripts in February 2003. The main objectives of the mission are to facilitate conservation and preservation of manuscripts 


\section{International Journal of Science and Research (IJSR) \\ ISSN (Online): 2319-7064}

Index Copernicus Value (2015): 78.96 | Impact Factor (2015): 6.391

through training, awareness, and financial support; and promote access to Indian manuscripts; to encourage scholarship and research in the study of Indian languages and manuscriptology; and to build a National Manuscript Library

\section{National Digital Library}

National Digital Library is initiated by Ministry of Human Resource Development Coordinated By IIT Kharagpur. It has currently 15, 38,083 items hosted including educational materials are available for users ranging from primary to post-graduate levels. There are more than 40 types of learning resources are available, items are available in more than 70 languages. Repository integrates contents from different Indian Institutional Repositories. Repository hosts contents from multiple subject domains like Technology, Science, Humanities, Agriculture and others. MHRD sponsored project hosts $10,000+$ video lectures in engineering domain; LibriVox consists of more than 2 Lakhs Audio books.

\section{Indira Gandhi Memorial Library, University of Hyderabad}

TAs well as being the first fully automated library in India, it was the first to begin a digital library program. Since 2002 the library has digitized around 250,000 pages, primarily theses and dissertations, as well as 300 books in English and Indian languages. The library has access to about 170,000 electronic journals. The library preserves discs that accompany printed books and journals by uploading them to the CD server, which is linked to the digital library system. The library scans printed journals from Indian publishers and maintains them in the digital library as well. The library uses the open source software D-space for its institutional repository.

\section{ETD and Institutional Repository}

Theses and dissertations are the bedrock of graduate education. Thesis and dissertation research is guided by experts in the field and frequently funded by highly competitive scholarships and grants. Theses and dissertations are useful sources of secondary information, particularly in the humanities, where texts are important and ideas stay current longer. Most of these works languish in college and university libraries and archives. Electronically publishing of theses and dissertations brings this valuable material more prominence. An Institutional Repository (IR) is a digital archive of the intellectual output of a university. Theses and dissertations are one basic category of material for an IR.

\section{Vidyanidhi Projects}

Vidyanidhi (which means "treasure of knowledge" in Sanskrit) is a digital archive of dissertations, as well as a set of resources for doctoral research in India. Vidyanidhi is being developed as a national repository and a consortium for electronic dissertations, through participation and partnership with universities, academic institutions, and other stakeholders. Vidyanidhi began as a pilot project in 2000with governmental support, well as support from the Ford Foundation and Microsoft India. The Ford Foundation support is for focusing on Social and Human Sciences. The Microsoft support is for the implementation of Unicode for
Indian Languages. Vidyanidhi is a member of the Networked Digital Library of Theses and Dissertations (NDLTD), and UNESCO and other efforts in this direction. UNESCO supports ETD initiatives worldwide.

\section{Electronic Theses and Dissertation Project of INFLIBNET Centre}

INLIBNET hosts a bibliographic database 200,000 dissertations from about two hundred Indian universities going back to 1905 . The Repository uses D-Space, which complies with the Open Archives Initiative (OAI) framework allowing publications to be easily indexed and searched by web search engines and other indexing services.

\section{Indian Institute of Astrophysics}

The Indian Institute of Astrophysics has its origins in the Madras Observatory, which was created in the late 18 th century. Today the Institute is a national research centre for physics and astronomy. Its repository includes dissertations from researchers associated with the Institute, as well as papers from the Bulletin of the Astronomical Society India beginning with volume 1 (1973), journal articles, and conference papers. Archival materials from the 18th, 19th, and 20th centuries have recently been added. These materials are manuscripts, photographs, annual reports, instruments and their descriptions. The repository uses DSpace.

\section{Raman Research Institute}

Raman Research Institute (RRI) is located in Bangalore, Karnataka state maintains digital repository for the research community benefits. It enables the research community to submit their preprints, postprints and other publications, using single web interface is being organized and kept in repository for easy retrieval of the information. The repository is developed with D-Space open source software complies with Open Archive Initiatives (OAI) framework, which facilitates to index and search by web search engines and other indexing tools. The contents available through RRI Digital Repository are approximately 5875, which includes

- Research publication of faculty and students

- Theses

- Annual Reports

- Collected papers of C.V. Raman

- Newspaper clippings

\section{Indian Institute of Technology, New Delhi}

Digital library initiatives began in 1998 with an upgrade to a faster Internet connection. The high speed Internet connection led to a number of digitized collections. IITs receive grants from government bodies such as AICTE (All India Council of Technical Education) and the Ministry of Human Resources Development and Management (MHRD) to develop digital libraries. Online courseware has been developed and older volumes of journals have been digitized, among other projects. More than 500dissertations are available in the repository. The campus has facilities for submitting material to there pository. More than 25,000 pages of journals were scanned and are available on the Institute intranet.

\section{Volume 6 Issue 1, January 2017




\section{International Journal of Science and Research (IJSR) \\ ISSN (Online): 2319-7064}

Index Copernicus Value (2015): 78.96 | Impact Factor (2015): 6.391

Indian Institute of Science, Bangalore

The Institute uses e-Prints, an institutional repository of research output. The archive is maintained by the National Center for Science Information (NCSI) and it supports selfarchiving in various file formats (pdf, Word, html, etc.) Around 5,000 articles are available.

\section{Indian Institute of Technology, Bombay}

The repository has bibliographic information and abstract for dissertations beginning in 1965. The masters thesis database has bibliographic information and abstract from 1999 on. More than 3,000 full text theses and Dissertations are available in the ETD database. The repository uses Greenstone, open source software, which complies with the Open Archives Initiative (OAI) protocol.

\section{National Institute of Technology, Calicut \\ "Nalanda" was initiated in 1999 and is one of the largest digital libraries in the country. It serves the campus with research and other academic information in science, engineering, and technology. The software used was developed by the institute itself. Nalanda is accessible from anywhere on campus. The repository contains theses and dissertations, course materials, articles, and annual reports.}

\section{National Institute of Technology, Rourkela}

Formerly known as Regional Engineering College (REC), this is one of the premier institutions for technical education in the country. NIT is a joint undertaking of Government of India and Government of Orissa. This Institutional Repository uses D-Space. At present around 343 documents are available in the repository.

\section{Problems for Digital Initiatives}

The digitization initiatives in India are encountered with several problems such as lack of technicalinfrastructure, trained manpower, finances and policy initiatives. Some of the important problems are discussed below:

- Lack of clear cut policy at National level with main focus on sustainability

- Outdated software and hardware and difficulty in upgrading the same.

- Non-availability of cost effective new technological advancement.

- Lack of multiple Indian language OCR facilities.

- Non-standard technical activities, data description and transmission characteristics.

- Non-availability of well-trained skilled personnel.

- Lack of management support

- Lack of proper preservation policy

- No Intellectual Property Rights policy for content development of digital information.

- Rigidity in the publishers' policies and data formats

\section{Conclusion}

Digital library initiatives in India are still in a promising stage of development. Many of the initiatives are one time projects with a limited grant, without proper planning for continuity. Important issues such as project objectives, preservation methods, content selection, and coordination with other similar initiatives, access mechanism, sustainability and cost factor should be addressed. The digital library concept in the Indian context is a new, that can become reality through projects and programmes funded by the government and the initiatives taken by the Libraries, which would like to develop a digital library, must make careful planning and undertake viability study, as digital library projects requires careful selection of hardware, software, materials and standards to be used in their preservation. The sustainability of digital libraries is difficult unless organisations have good budgetary support and quality manpower.

\section{References}

[1] Kamble, V. T., Raj, H. \&Sangeeta,Open Source Library Management and Digital Library Software. DESIDOC Journal of Library \& Information Technology, 32(5), (2012), 388-392.

[2] Bansode, S., \& Pujar, S. M,Scholarly Digital Library Initiatives: World Versus India. DESIDOC Journal of Library \& Information Technology, 28(6),(2008),21-26.

[3] Varatharajan, N., \&Chandrashekara, M, Digital Library Initiatives at Higher Education and Research Institutions in India. Library Philosophy and Practice, (2007), 1-7.

[4] Mittal, R., \& Mahesh, G. Digital libraries and repositories in India: an evaluative study. Program, 42(3), (2008), 286-302.

[5] Oehlerts, B., \&Liu, Digital preservation strategies at Colorado State University Libraries. Library Management, 34(1/2),(2012),83-95.

[6] Jones, M,The digital preservation coalition. VINE, 34(2), (2004), 84-86.

[7] Biswas, G.\& Paul, D. An evaluative study on the open source digital library softwares for institutional repository: Special reference to Dspace and greenstone digital library, International Journal of Library and Information Science, 2(1), (2010), 1-10.

[8] Dhamdhere, S. N\& LihitkarR,Open Source Software: Boon to Digital Libraries, International Journal of Advanced Library and Information Science, 1(1), (2013), 7-22.

Volume 6 Issue 1, January 2017

www.ijsr.net

Licensed Under Creative Commons Attribution CC BY 